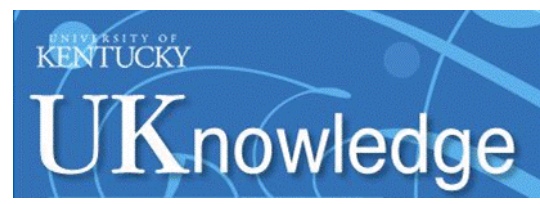

University of Kentucky

UKnowledge

\title{
Trends in Mental Health of an Adolescent Medicine Clinic Patient Population
}

\author{
Abdel Salous \\ University of Kentucky, abdel.salous@uky.edu \\ Linah Al-Alem \\ University of Kentucky, linah.al-alem@uky.edu \\ Hatim A. Omar \\ University of Kentucky, hatim.omar@uky.edu
}

Follow this and additional works at: https://uknowledge.uky.edu/pediatrics_facpub

Part of the Pediatrics Commons

Right click to open a feedback form in a new tab to let us know how this document benefits you.

\section{Repository Citation}

Salous, Abdel; Al-Alem, Linah; and Omar, Hatim A., "Trends in Mental Health of an Adolescent Medicine Clinic Patient Population" (2009). Pediatrics Faculty Publications. 77.

https://uknowledge.uky.edu/pediatrics_facpub/77

This Article is brought to you for free and open access by the Pediatrics at UKnowledge. It has been accepted for inclusion in Pediatrics Faculty Publications by an authorized administrator of UKnowledge. For more information, please contact UKnowledge@lsv.uky.edu. 


\section{Trends in Mental Health of an Adolescent Medicine Clinic Patient Population}

Digital Object Identifier (DOI)

http://dx.doi.org/10.1515/IJAMH.2009.21.1.9

\section{Notes/Citation Information}

Published in International Journal of Adolescent Medicine and Health, v. 21, no. 1, p. 9-14.

(C) Freund Publishing House Ltd.

The copyright holder has granted permission for posting the article here.

Reprinted as a book chapter in Mental Health from an International Perspective. Joav Merrick, Shoshana Aspler, \& Mohammed Morad, (Eds.). p. 187-192.

Reprinted as a book chapter in Rural Child Health: International Aspects. Erica Bell, \& Joav Merrick, (Eds.). p. 237-242. 


\title{
Trends in mental health of an adolescent medicine clinic patient population
}

\author{
Abdel Salous, $\mathrm{MSci}^{1}$, Linah Al-Alem, $\mathrm{MSci}^{2,3}$ and Hatim A Omar, $\mathrm{MD}^{4}$
}

'University of Kentucky College of Medicine MD/PhD Program, ${ }^{2}$ Department of Molecular and Biomedical Pharmacology, ${ }^{3}$ Obstetrics and Gynecology, University of Kentucky College of Medicine, ${ }^{4}$ Division of Adolescent Medicine, Department of Pediatrics, University of Kentucky College of Medicine, Lexington, USA

Abstract: The correlation between exposure to forms of violence and development of mental disorders in victims is well established. The purpose of this paper was to identify mental health problems in an adolescent medicine clinic population in Lexington, $\mathrm{KY}$ and to investigate potential correlation of mental disorders with psychosocial factors. Data were gathered from the charts of 169 adolescent clinic patients (age 10-22) seen in the clinic for mental health care and analyzed using Excel. Of the patient population, $68 \%$ were urban, whereas $32 \%$ were rural. In terms of gender, $40 \%$ of the patients were male and $60 \%$ were female, $80 \%$ were white, $13 \%$ black, and $7 \%$ had other racial background(s). The most prevalent mental disorders in this group were depression $32.12 \%, 13 \%$ with generalized anxiety disorder, 8.2\% with an attention deficit disorder (including ADHD), and 5.76\% with an adjustment disorder. The abovementioned demographic trends showed that depression continues to be the most common mental health problem in this population regardless of gender, ethnic origin, or economic status. This finding highlights the need for availability of mental health support to this patient population. Further work is needed to spotlight the most significant psychosocial factors and root causes of mental health conditions in this age group.

Keywords: Adolescents, mental health, characterization, trends

Correspondence: Professor Hatim A Omar, MD, Department of Pediatrics, Room J422, University of Kentucky, Lexington, KY 40536-0284 United States. Tel: 859-323-5643; Fax: 859-257-7706; Email: haomar2@uky.edu

Submitted: April 05, 2008. Revised: May 01, 2008. Accepted: May 12, 2008.

\section{INTRODUCTION}

By the year 2020, adolescents representing individuals in the 10 to 22 year-old age range are expected to compose $14 \%$ of the United States population (1). Adolescence is a challenging transition phase with physical, cognitive, and emotional changes, all of which can have a significant impact on mental health (2). Epidemiologic data from the World Health Organization show that $20 \%$ of all adolescents worldwide have one or more mental or behavioral health problems (3). In addition, up to $50 \%$ of all adult mental disorders have been shown to have their onset in adolescence (3). This early onset of disease becomes more critical when a common mental disorder like depression is expected to show a rising trend during the coming 20 years of their lives (3). Moreover, although the incidence of depression peaks during middle age, depression is increasingly being recognized 
during adolescence and young adulthood (4).

Approximately $20 \%$ of depressives end their lives by committing suicide (5). With respect to adolescents, suicide attempt rates were highest among adolescents 15-19 years old (6). In addition, completed suicide remains among the top three causes of death in the population aged 15-34 years in both males and females (3). Other mental disorders, such as adjustment disorders, lead to psychosocial impairment, problems with the legal system, and restlessness (7). As for attention deficit and hyperactivity disorders, these in turn have a negative impact on scholastic performance, social relationships, and social behavior (8). Overall, the effect of mental disorders on society accounts for over $15 \%$ of the burden of disease in the United States, surpassing the disease burden caused by all cancers (9). In economic terms, children with mental health disorders impose a greater load on their parents to cut work hours, to quit work, and to spend more time arranging their child's care compared with children with other healthcare needs (10).

The causes of mental disorders in adolescents are complex and may evolve from a wide variety of psychosocial stressors, physical injuries, developmental changes, exposure to various forms of abuse, genetics, and cultural influences (4, 11-13). To better characterize the relative impact of the various psychosocial factors on the development of mental disorders, this study examined and reported on a sample of an outpatient adolescent clinic patients in Lexington, Kentucky. The patients were recipients of either counseling or medical services for mental disorders for which they were diagnosed. Specifically, the study sought to describe retrospectively this patient population with respect to demographic profile, age, gender, racial background, socioeconomic status (SES), marital status, educational level, and prevalent mental disorders. The descriptive analysis in this paper is deemed to give rise to further investigation of the most significant psychosocial factors precipitating the onset of mental disorders in adolescents.

\section{METHODS}

Medical chart review was conducted for 174 patients, who received counseling or therapy for diagnosed mental disorders. Patients received psychological therapy services regularly on an outpatient basis for mental health. In addition, medical services were provided for other physical conditions patients presented with at the time of the visit. The patients' data were entered into a spreadsheet program for further analysis.

Patients were excluded from the study if they did not meet the age requirements (1022 years) at the time of data collection and if their charts lacked documentation regarding mental disorders or conditions. With all exclusions, the final sample size was 169 patients. The different variables were entered in separate columns, grouped, codified, and analyzed statistically using Excel functions.

\section{RESULTS}

The age range of the patients included in the study was 10-22 years at the time of the study. The mean age was 15.6 years and the median age was 16 years, while the mode value for age was 17 years (see table 1). As expected, most of the patient population was urban $(68 \%)$. The remaining $32 \%$ came from the surrounding rural areas such as Montgomery, Anderson, and Jessamine counties in addition to others (table 2). In terms of gender, $40 \%$ of the patients were male and $60 \%$ were female (see table 2 ). 
Table 1: Age profile of subjects in the study $(n=169)$

\begin{tabular}{lccc}
\hline \multirow{2}{*}{ Age Range } & Min & Max & \\
\cline { 2 - 4 } & 10 & 22 & \\
\hline \multirow{2}{*}{ Age Distribution } & Mean & Median & Mode \\
\cline { 2 - 4 } & 15.6 & 16 & 17 \\
\hline
\end{tabular}

As expected, the majority of the patient population was urban $(68 \%)$. The remaining $32 \%$ came from the surrounding rural areas such as Montgomery, Anderson, and Jessamine counties in addition to others (table 2). In terms of gender, $40 \%$ of the patients were male and $60 \%$ were female (see table 2).

The type of in insurance plan was documented as an indicator of SES either as high or low. Of all patients, almost twothirds carried an insurance plan reflecting high SES, with the remainder reflecting a low SES. The latter patients either received financial assistance or were carriers of other non-private insurance.

Ethnic background showed that the vast majority of patients were white, $13 \%$ black, and the rest had other racial backgrounds, including Hispanic and mixed racial background. With regard to marital status, almost all patients reported their status as single, with only $1 \%$ as married and $1 \%$ as other. The educational profile showed that two-thirds of the patients were in high school, almost one-quarter in middle school, and only $5 \%$ in college. The remaining $5 \%$ included dropouts and patients with other educational arrangements including home schooling.

Table 2: Demographic characteristics of subjects in the study $(n=169)$.

\begin{tabular}{lccc}
\hline Geographic Distribution & Urban & Rural & \\
& $68 \%$ & $32 \%$ & \\
Gender Distribution & Female & Male & \\
& $60 \%$ & $40 \%$ & \\
Socioeconomic Status* & High & Low & \\
& $61 \%$ & $39 \%$ & \\
Ethnic Background** & White & Black & Other \\
& $80 \%$ & $13 \%$ & $7 \%$ \\
Marital Status & Single & Married & Other \\
& $98 \%$ & $1 \%$ & $1 \%$
\end{tabular}

Educational Level*** High School Middle School College Other

$67 \%$

$23 \%$

$5 \% \quad 5 \%$

* The insurance plan was documented as an indicator of socioeconomic status (SES). High SES patients were carriers of a private insurance plan while low SES patients were carriers of other non-private insurance plans such as state medical assistance or no insurance. ${ }^{* *}$ Other includes Hispanic, mixed racial origin and unspecified racial origin. ${ }^{* * *}$ Other includes dropouts, home schooling, and other educational arrangements 


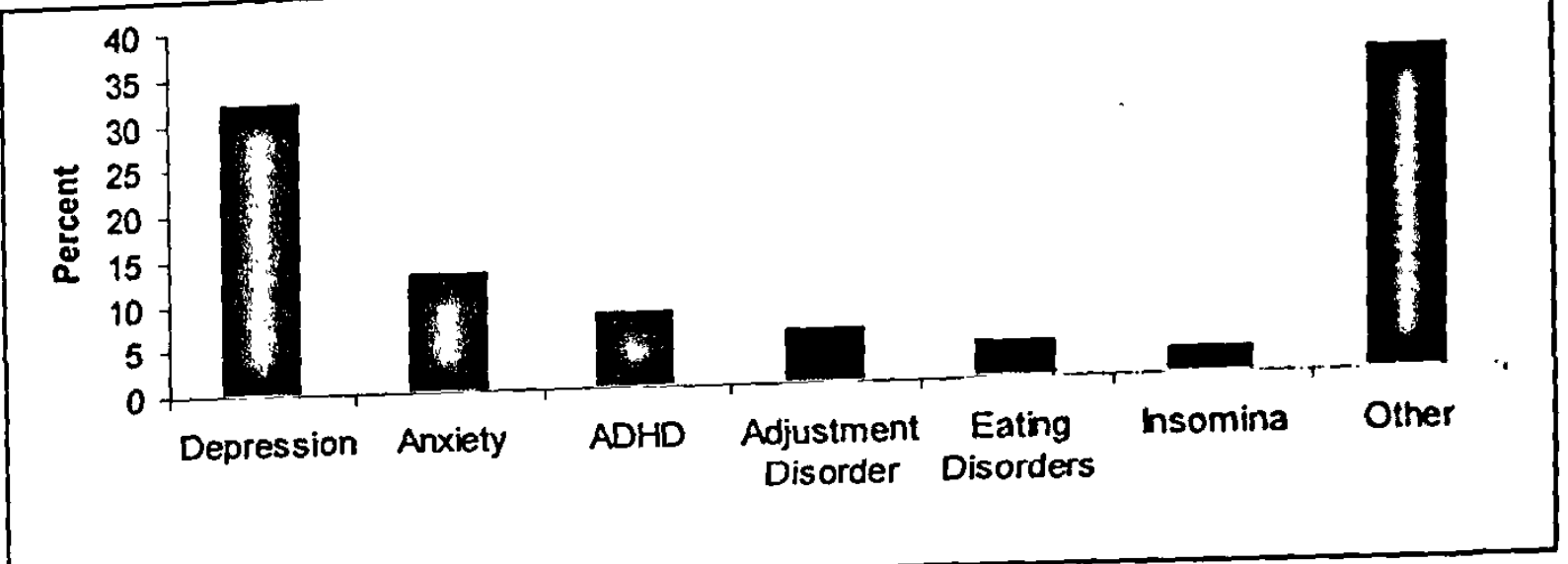

Fig. 1: Prevalence of mental disorders $(n=169)$

\section{Mental disorders}

Figure 1 shows that the most prevalent mental disorders in this group are depression, generalized anxiety, ADHD, and adjustment disorders in the listed order; of the patients, $32.1 \%$ were diagnosed with a depression disorder, whereas $13.0 \%$ were diagnosed with a generalized anxiety disorder; $8.2 \%$ had an attention deficit disorder (including ADHD), and $5.8 \%$ an adjustment disorder. Eating disorders (including both bulimia and anorexia nervosa $3.9 \%$ ) and insomnia accounted for $2.7 \%$. The remaining mental disorders grouped under 'other' include anger management, Asperger's syndrome, bipolar disorder, conversion disorder, obsessive-compulsive disorder, pain disorder, panic disorder, post-traumatic stress disorder, and trichitillomania.

\section{DISCUSSION}

The goal of this study was to characterize a representative outpatient adolescent population receiving treatment for mental health. The mean, median, and mode values for age shown in table 1 are indicative of a higher incidence of mental health disorders during high school age.

The higher incidence of mental health disorders in urban areas as represented by two-thirds of the patients (table 2) may reflect the additional stressors of urban life compared with rural settings. Altematively, the proximity of urban dwellers to an urban healthcare facility may play a role in this distribution. In turn, this could indicate a greater need for mental health services in this sector of the adolescent population. This demographic trend could also be attributed to the insufficiency of medical services in rural areas.

The ratio of female to male patients (table 2) points to a higher prevalence of mental disorders among women versus men. This trend is agrees with mood disorder rates of $5 \%$ to $12 \%$ for men and $10 \%$ to $25 \%$ for women ages 15 years and older (14). An alternative explanation for this trend is that women could have a higher susceptibility than men to psychosocial factors. For example, compared with men, violence, socioeconomic disadvantage, low income, low or subordinate social status and rank are all psychosocial factors that affect women disproportionately (15). In addition, women are more vulnerable to forms of abuse and their associated development of mental disorders $(15,16)$. Additionally, according to the National Survey on Drug Use and Health (17), compared with men, women with substance abuse disorders are more likely to seek treatment.

As for SES, almost two-thirds of the patients had private insurance plans, 
defined as high SES, whereas low SES patients were carriers of medical assistance plans or no insurance. The potential correlation between SES and types of mental disorders poses an interesting question to be explored in future studies.

The racial breakdown shown in table 2 roughly parallels the national racial distribution-75\% white, $12 \%$ African American, $3.6 \%$ Asian, and $2.4 \%$ with mixed racial backgrounds (18). Although the racial diversity closely matches the national averages, it is important to recognize the wider variation that may exist in other communities. For example, rural and inner city communities may deviate significantly from these trends. The educational profile clearly shows that high school students were the major recipients of mental health services in this clinic. The most prevalent mental disorder in this group was depression, followed by anxiety disorders. Unfortunately, the prevalence of mental disorders in adolescents has not been as well documented as that for adults (2).

This study sought to provide a brief description of an adolescent patient population receiving mental healthcare services in an outpatient clinic. This goal was accomplished by reporting on the demographic characteristics and the most prevalent mental disorders in this patient sample. We conclude that mental health issues are a significant problem in adolescents, with depression as the most common disorder. Access to mental health care is therefore crucial to help prevent consequences (such as suicide) and to help teens grow into healthy adults.

\section{ACKNOWLEDGMENTS}

The authors would like to thank Dr. Marlene Huff, Dr. Kimberly McClanahan, Ms. Elizabeth Johnson, and Ms. Heidi Smith for their help in data collection and advice.

\section{REFERENCES}

1. Kolbe L. Adolescent health: population as patient. Adolescent health leadership forum. Elm Groove, IL: Am Acad Pediatrics, 2003. Available at: http:// www.aap.org/advocacy/ahproject/AHL PopulationasPatientLKolbe.pps.

Accessed 5 May 2008.

2. Satcher D. Mental health: A report of the surgeon general. Prof Psychol Res Pr 2000;31(1):5-13.

3. World Health Organization (WHO). The world health report. Mental health: New understanding, new hope. Geneva: WHO, 2001:19-41.

4. Lewinsohn PM, Hops H, Roberts RE, Seeley JR, Andrews JA. Adolescent psychopathology: 1. Prevalence and incidence of depression and other DSM-III-R disorders in high school students. J Abnorm Psychol 1993;102 (1):133-44.

5. Goodwin FK, Jamison KR. Suicide. Manic-depressive illness. New York: Oxford Univ Press, 1990:227-46.

6. Suicide Prevention Resource Center, 2004. United States Suicide Fact Sheet. Available at: http://www.sprc.org/state information/PDF/statedatasheets/sprc national_data.pdf. Accessed 5 May 2008.

7. Pelkonen M, Marttunen M, Henriksson M, Lonnqvist J. Adolescent adjustment disorder: precipitant stressors and distress symptoms of 89 outpatients. Eur Psychiatry 2007;22(5):288-95.

8. Lauth GW, Heubeck BG, Mackowiak K. Observation of children with attentiondeficit hyperactivity (ADHD) problems in three natural classroom contexts. $\mathrm{Br} \mathbf{J}$ Educ Psychol 2006;6(Pt 2):385-404.

9. National Institute of Mental Health (2008). Mental health statistics. http:// www.nimh.nih.gov/health/statistics/in dex.shtml. Accessed 5 May 2008. 
10. Busch SH, Barry CL. Mental health disorders in childhood: assessing the burden on families. Health Aff 2007; 26(4):1088-95.

11. Fisc her T, Koch P, Saager C, Kohut $G N$. The radio-radial external fixator in the treatment of fractures of the distal radius. J Hand Surg [Br] 1999; 24(5):604-9.

12. Kessler RC, Davis CG, Kendler KS. Childhood adversity and adult psychiatric disorder in the US National Comorbidity Survey. Psychol Med 1997; 27(5):1101-19.

13. MacMillan HL, Fleming JE, Streiner DL, Lin E, Boyle MH, Jamieson E, et al. Childhood abuse and lifetime psychopathology in a community sample. Am J Psychiatry 2001;158 (11):1878-83.

14. Waraich P, Goldner EM, Somers JM, Hsu L. Prevalence and incidence studies of mood disorders: a systematic review of the literature. Can J Psychiatry 2004;
49(2):124-38.

15. World Health Organization (WHO). Gender and women's mental health: Gender disparities and mental health: The facts. Available at: http://www. who.int/mental_health/prevention/gen derwomen/en/. Accessed 5 May 2008.

16. Sanci L, Coffey C, Olsson C, Reid S, Carlin JB, Patton G. Childhood sexual abuse and eating disorders in females: findings from the Victorian Adolescent Health Cohort study. Arch Pediatr Adolesc Med 2008;162(3):261-7.

17. Substa nce Abuse and Mental Health Services Administration. National survey on drug use and health, 2004. Available at: http://www.oas.samhsa, gov/NSDUH/2k4nsduh/2k4Results/2k 4Results.pdf Accessed 5 May 2008.

18. U.S. Department of Commerce. U.S. Census Bureau, 2000. Available at: http://www.census.gov/. Accessed 5 May 2008. 